\title{
La racionalidad de los impuestos. Una tarea de reconciliación
}

\author{
The Rationality of Taxes. A Task of \\ Reconciliation
}

Francisco Saffie

Recepción: 21/12/2018

Evaluación: 29/03/19

Aceptación final: 08/04/19

Resumen: Este artículo parte de un diagnóstico sobre los problemas centrales del derecho tributario contemporáneo en un contexto neoliberal: la falta de justificación y la falta de cumplimiento de los deberes impositivos. Estos problemas se explican por un paradigma clásico basado en una visión egoísta y racional de individuo, una fundamentación instrumental de los impuestos y una concepción de la propiedad privada como un derecho natural. Ante este panorama, se realiza una reconstrucción alternativa de la racionalidad de los tributos a partir de las ideas de filosofía del derecho de Hegel. De esta manera, se presenta una propuesta que busca establecer una justificación no instrumental de los impuestos y superar la oposición entre tributos y propiedad privada.

Palabras claves: derecho tributario, legitimidad, elusión, Hegel, propiedad privada

Abstract: This article begins with a diagnosis of the central problems of contemporary tax law in a neoliberal context: the lack of justification and

PhD in Law, University of Edinburgh, Reino Unido. Profesor Asistente, Universidad Adolfo Ibáñez, Santiago de Chile. Post-Doctoral Global Fellow, New York University, Estados Unidos. Correo electrónico: francisco.saffie@uai.cl. 
the failure to comply with tax duties. These problems are explained by a classic paradigm based on a selfish and rational vision of the individual, an instrumental foundation of taxes and a conception of private property as a natural right. In view of this scenario, an alternative reconstruction of the rationality of taxation is made on the basis of Hegel's ideas of Philosophy of Law. In this way, a proposal is presented that aims to establish a non-instrumental justification of taxes and to overcome the opposition between taxes and private property.

Keywords: tax law, legitimacy, avoidance, Hegel, private property

\section{Introducción}

El derecho tributario contemporáneo se enfrenta a dos tipos de problemas. El primero es uno de justificación o de legitimidad de la institución; el segundo, es uno de cumplimiento. El primer problema aparece cuando se debe justificar la necesidad de los impuestos en un mundo dominado por políticas económicas neoliberales; el segundo, cuando quienes entienden los sistemas tributarios como condición de posibilidad de obtener igualdad económica observan que el derecho tributario actual es susceptible de quedar sin aplicación por conductas estratégicas de los contribuyentes, tales como la elusión y la evasión tributaria. En este trabajo propongo un diagnóstico del estado actual del derecho tributario y discuto críticamente algunas soluciones que se han propuesto a estos dos problemas. Argumentaré que las soluciones propuestas en estos dos niveles son inadecuadas porque no son capaces de dar cuenta de la racionalidad subyacente en el derecho tributario, puesto que se construyen a partir de justificaciones que contraponen intereses individuales con intereses colectivos aparejadas de justificaciones puramente instrumentales (tanto de los impuestos como del derecho tributario). En lo que sigue, el argumento se estructura de la siguiente forma: en la primera parte se ofrece un diagnóstico de los problemas que atraviesa el derecho tributario a nivel local y global en un mundo caracterizado por una hegemonía neoliberal; en la segunda, una reconstrucción teórica del estado actual del derecho tributario que explica por qué surgen esos problemas; en la tercera y cuarta parte se revisan crí- 
ticamente algunas soluciones a los problemas de legitimidad y de aplicación del derecho tributario; en la quinta parte, para finalizar, se esboza una reconstrucción alternativa de la racionalidad del derecho tributario en líneas de la filosofía del derecho de Hegel.

\section{Los problemas de legitimidad del derecho tributario}

Tanto a nivel local como a nivel global, los impuestos han dejado de cumplir sus funciones de redistribución y financiamiento del gasto público. Estas funciones que caracterizan al derecho tributario en los estados modernos y que se identifican con las condiciones que hacen posible la igualdad que requieren los sistemas políticos democráticos, ha sido dejada de lado tanto por una discusión que pone en duda la legitimidad de la redistribución como porque el derecho tributario es incapaz de concretar las consecuencias legales que debería, esto es, la generación de obligaciones de pagar una determinada suma de dinero en beneficio fiscal. El primer problema tiene componentes políticos y económicos; el segundo, es un problema jurídico condicionado por las comprensiones políticas y económicas de los impuestos.

El problema de la legitimidad de la redistribución de los sistemas tributarios es un proceso que comenzó a fines de la década de los 70 del siglo pasado y que se ha acrecentado en nuestros días. La influencia del neoliberalismo es quizá la principal causa que explica la forma en que los sistemas tributarios dejaron de realizar su función de redistribución al haber perdido su vinculación con la democracia. Hoy los impuestos han perdido su sentido o racionalidad puesto que aparecen como una institución en virtud de la cual el Estado exige contribuir sin dar nada a cambio. Aún más, la disminución del gasto social en que están embarcados los gobiernos a nivel global pareciera justificar no pagar impuestos, mientras que, al mismo tiempo, la mayor parte de los recursos generados en los mercados se entiende que corresponden, sin mayor discusión, a quienes son los dueños del capital. En otras palabras, se ha consolidado "el libertarianismo propio de cada día” (Murphy y Nagel, 2002) que ve una disociación entre impuestos y propiedad. Vale decir, hasta hoy sigue primando la idea que 
el derecho de propiedad es un derecho natural anterior a la formación del Estado y que los impuestos son una restricción a ese derecho. ${ }^{1}$

En Buying Time, Wolfgang Streeck argumenta que desde los años 70 en adelante operó una redefinición del rol de las instituciones políticas que caracterizan al Estado moderno. Esa redefinición se explica, a juicio de Streeck, porque el orden económico neoliberal ha transformado el sentido de las instituciones políticas restándoles su capacidad de equilibrar los intereses de la democracia y del capital, especialmente porque se ha producido una pérdida del poder de la democracia para definir políticas que beneficien a quienes no son propietarios del capital. En esa década el capital decidió poner en cuestión el contrato social post segunda guerra mundial, ese desacuerdo llevó al fin de las políticas económicas keynesianas adoptadas hasta entonces por las democracias occidentales. En ese momento se comienzan a terminar dos características de aquel período: la paz y el estado de bienestar. Al abandonar el contrato social de posguerra, el Capital condicionó el funcionamiento del Estado dejando de invertir cuando las expectativas de los trabajadores comenzaron a crecer y se hicieron difíciles de controlar. El Capital, entonces, decidió exigir una parte mayor del producto social. Según Streeck, la crisis económica de fines de los 70 -y las crisis económicas que le siguieron- se comprenden mejor si se entiende al Capital de esta manera. El Capital, ahora constituido en un agente político y económico autoconsciente, condicionó la forma en que el Estado podía financiar sus actividades y quedó en posición de generar crisis económicas cada vez que sus beneficios económicos eran menores a los que esperaba obtener. De esta manera, devino más poderoso que aquella parte de la población que depende del capital al momento de fijar las condiciones de la constitución económica del Estado (Streeck, 2014, pp. 6-26). Los nuevos acuerdos sociales entre el Capital y los Estados explican las políticas que llevaron a la disminución y rebaja de impuestos con la consecuente pérdida de recaudación. La primera reacción de los gobiernos fue disminuir las cargas impositivas al capital y luego implementar políticas que permitieron la liberalización de los mercados y el flujo del capital, al abrir las fronteras y eliminar los controles financieros. Esto dio paso a lo que Streeck llama 
el "Estado deudor" (2014, pp. 47-96): los estados decidieron mantener el Estado de Bienestar, financiándolo esta vez no con el producto de la recaudación tributaria sino con deuda pública. La tercera fase y final de esta evolución del Estado llevó a la "política del estado de consolidación" internacional causada por la deuda acumulada (pp. 97-164). Las políticas del Estado de consolidación se caracterizan por un movimiento doble: a nivel local, los gobiernos disminuyen el gasto público implementando políticas de austeridad, siguen disminuyendo la carga tributaria especialmente al capital y los mercados financieros, y se privatizan los servicios públicos; a nivel global, especialmente en Europa, los Estados entraron en estructuras de integración internacional que dificultaron todavía más la toma de decisiones mediante procedimientos democráticos porque dieron un poder desproporcionado al Capital para presionar por la adopción de políticas neoliberales. Streeck argumenta que esta evolución del Estado, que es causalmente dependiente de las políticas económicas que se han adoptado durante los últimos treinta o cuarenta años, solo ha demorado la crisis del capitalismo democrático, incrementando el poder del Capital en detrimento de la democracia. Streeck es pesimista respecto del futuro del estado democrático, puesto que cree que este "proceso de desdemocratización del Capitalismo a través de la deseconomización de la democracia” llevará la democracia redistributiva a su fin y la dejará reducida a "una combinación del estado de derecho con entretención pública” (Streeck, 2014, p. 5).

Sin embargo, hay quienes argumentan que las políticas neoliberales han mejorado la calidad de vida de las personas en el mundo, especialmente en los países en vías de desarrollo ${ }^{2} \mathrm{Al}$ menos en términos materiales, sostienen quienes defienden esas políticas, los individuos tienen acceso a productos y bienes, tales como un automóvil o un refrigerador que, por ejemplo, en el caso de Chile, no podían adquirir treinta años atrás. Este "bienestar" sería el resultado del funcionamiento del libre mercado como un sistema de información que permite la producción y distribución eficiente de recursos. En este esquema el rol del Estado consiste en asegurar las condiciones institucionales que permiten el funcionamiento del mercado.

2 Un argumento que muestra la forma en que las políticas neoliberales generan desarrollo económico. Véase (Paus, 1994). 
Colin Crouch llama "neoliberales puros" a quienes defienden esta comprensión del neoliberalismo (2013, p. 23) Esta concepción pura del neoliberalismo, según argumenta Crouch, no existe en las polis existentes hoy. Por el contrario, lo que se encuentra una vez que se analiza en detalle la relación entre orden económico y orden político que ha producido el neoliberalismo es lo que Crouch llama "el neoliberalismo realmente existente" (2013, p. 24). Este tipo de neoliberalismo se caracteriza por el poder que tienen las empresas multinacionales que son capaces de hacer de manera exitosa lobby por sus intereses y, de forma más general, por el poder que la riqueza privada tiene en la política. Según Crouch, el neoliberalismo realmente existente "produce una economía politizada muy lejana a lo que los economistas entienden por economía liberal de mercado, y una política tan desbalanceada por el poder plutocrático que compromete seriamente la idea de la democracia liberal" (2013, p. 24). En este sentido, el neoliberalismo realmente existente asegura la posición política y los privilegios de aquellos que obtienen beneficios derivados de las interacciones de mercado. Conforme al neoliberalismo realmente existente, las desigualdades económicas conllevan desigualdades de poder político. La función del Estado bajo el neoliberalismo se ha reducido a asegurar los efectos de la distribución del mercado, para lo que ha sido crucial la defensa de la protección legal que han recibido una determinada concepción de la propiedad privada y del estado de derecho. Mientras que el discurso neoliberal intenta convencer a los individuos que esto es todo lo que se requiere por parte del Estado puesto que la obtención de beneficios económicos dependerá exclusivamente de cuán bien lo hagan en las interacciones de mercado, esto es de su esfuerzo personal y de su responsabilidad, los propios neoliberales toman control del Estado para asegurarse que esta promesa no se cumpla. Así, lo que parece una promesa de bienestar individual abierta a todos, realmente no lo es. En esta línea, David Harvey argumenta que el neoliberalismo no ha traído el bienestar de todos, como promete, sino la "restauración del poder de clases" (Harvey, 2006, p. 26) ${ }^{3}$ a través de un proceso de acumulación por desposesión (p. 43). Este proceso consiste en redistribuir el producto social a los dueños del capital quienes, a su vez, se benefician de 
una baja carga tributaria y del precio que reciben por la prestación de los servicios que antes prestaba el Estado. ${ }^{4}$

Nos encontramos en un momento histórico en que el proceso de neoliberalización de la política económica se ha vuelto global. Lo que comenzó como una tímida política de mercados abiertos devino en una esfera de poder dominada por los intereses económicos globales del Capital. En este escenario, las empresas multinacionales son los verdaderos ciudadanos del mundo, o como sostiene Crouch, las compañías globales se transformaron en "las instituciones claves del mundo posdemocrático" (Crouch, 2004, p. 31) Esas compañías son las que se benefician directamente de la libertad de movimiento de los flujos de capital en el mundo, la falta de restricciones al comercio, instancias internacionales de resolución de conflictos comerciales orientadas a incentivar el comercio internacional y, en especial, de una baja carga tributaria a nivel global. Siguiendo a Crouch, las empresas multinacionales obtuvieron estos beneficios al sobrevivir en un mundo en que los más duros tienen asegurados los mejores resultados. Una vez que estas firmas lograron establecerse a nivel global, tuvieron el poder de condicionar sus inversiones para obtener regímenes fiscales y laborales privilegiados (Crouch, 2004, p. 32) Al mismo tiempo, los Estados entraron en una competencia por obtener recursos de estas compañías confiriéndoles toda clase de privilegios regulatorios. Esta es la forma en que se ha vuelto común a nivel global encontrar políticas tributarias con regímenes de no tributación, tales como beneficios tributarios de diferimiento del pago de impuestos para las ganancias de capital o exenciones tributarias a la ganancia de capital obtenida en la enajenación de acciones transadas en bolsas u otros beneficios en las ganancias obtenidas en los mercados financieros, por ejemplo, en bonos.

Sin embargo, los Estados han tenido que mantener parte del financiamiento del gasto público a través del sistema tributario ${ }^{5}$ La clase media ha sido la responsable de la carga económica asociada al funcionamiento del

4 Véase también (Crouch, 2004, pp. 31-69) y (Crouch, 2011).

5 La gran mayoría de los países financia el gasto público con una combinación de recaudación fiscal y deuda pública. Este no es el caso de Chile que, como país neoliberal consecuente, la deuda pública ha estado estrictamente controlada a través de una regla de balance estructural. Según esta regla el gasto público no puede exceder la recaudación tributaria. Esta regla no ha sido del todo respetada en los últimos tres gobiernos, donde se 
Estado. De esta manera es fácil ver cómo los sistemas tributarios pierden su legitimidad bajo las políticas del neoliberalismo realmente existente. En primer lugar, los impuestos directos dejan de cumplir su función tradicional de asegurar ciertos niveles de redistribución porque el capital y las utilidades económicas pueden moverse fácilmente de una jurisdicción a otra sin carga tributaria o con una menor carga tributaria, en caso de que no reciban el trato económico privilegiado que desean. En segundo lugar, los sistemas tributarios descansan fuertemente en impuestos indirectos para obtener la recaudación fiscal que necesitan. Esto implica que quienes pagan dichos impuestos son quienes obtienen sus rentas del trabajo (y no del capital) y aquellos que no pueden mover fácilmente sus recursos a otra jurisdicción. Finalmente, el sistema tributario deviene opresivo, ya que el Estado no da nada a cambio a sus ciudadanos. En un sistema neoliberal cada uno de los individuos debe costear sus propias pensiones, salud, educación, etc., mientras que al mismo tiempo no pueden acumular capital. Llamo a este proceso la "falta de sentido económico de los sistemas tributarios" bajo el neoliberalismo. ${ }^{6}$ Pero esta no es la única forma en que los sistemas tributarios han perdido sentido bajo el neoliberalismo.

El neoliberalismo también ha hecho que los sistemas tributarios pierdan su sentido político, por lo que quiero decir: se ha producido una disociación entre los impuestos y las obligaciones de solidaridad propias de la ciudadanía. Según Wendy Brown, el neoliberalismo no es solo un conjunto de políticas económicas sino también "un orden normativo de la razón" que "metamorfosea todos los dominios y esfuerzos humanos, junto con los propios seres humanos, de acuerdo con una imagen específica de lo económico" (Brown, 2015, pp. 9-10 y cap. 11) Brown argumenta que el neoliberalismo ha extendido el "modelo del mercado a todos los dominios y actividades" y "configura a los seres humanos exclusivamente como actores de mercado, siempre, solamente, y en todo lugar como homo economicus" (p. 31) En este sentido, el neoliberalismo es distinto del liberalismo económico

ha aceptado un nivel de deuda pública superior a la recaudación fiscal. Curiosamente dos de esos gobiernos han sido de derecha.

6 Para una exposición del argumento neoliberal como argumento económico, según el cual los impuestos "se vuelven inconsecuentes", véase (Kleinbard, 2014, pp. 37-41). 
clásico (p. 33) Esta idea normativa que acompaña al neoliberalismo invade lo político, haciendo a un lado al homo politicus del intercambio político para transformar "los principios de justicia democráticos en un idioma económico" (Brown, 2015, p. 35), con consecuencias importantes para las instituciones democráticas. La idea normativa del neoliberalismo entiende a los individuos como unidades de capital humano que compiten con otros, o cuando más como agentes económicos que comparten el riesgo de la vida económica (como ocurre en cualquier organización comercial en términos jurídicos) que, por lo mismo, no reciben protección alguna incluso bajo los supuestos de una noción liberal del contrato social (Brown, 2015), destruye la noción de solidaridad que justificaba los sistemas tributarios progresivos. Contrario a la lógica normativa de los mercados, uno de los bienes públicos más importantes de las comunidades políticas es la solidaridad. La solidaridad es un bien público o colectivo en el sentido que es "indivisible y debe ser producido, o al menos decidido, por quienes se benefician de su existencia" (Streeck, 2012, p. 41) En este sentido, se trata de uno de aquellos bienes que son parte de las comunidades política entendidas como "comunidades de destino" (Streeck, 2012, p. 42). El pago de impuestos es la forma paradigmática en que "la calidad de ciudadano demanda que uno provea de apoyo generalizado a la comunidad como un todo... para que pueda ser usado para fines todavía indeterminados por un gobierno legalmente constituido" (Streeck, 2012, p. 42) En este sentido, los impuestos son parte de aquellas obligaciones que definen y constituyen la ciudadanía.

\section{Una reconstrucción teórica del estado actual del derecho tributario. El paradigma clásico}

Una de las razones que a mi juicio explica los problemas de legitimidad del derecho tributario se encuentra en los presupuestos sobre los que se construyó el diseño institucional del derecho tributario actual. El punto es que ese diseño institucional asume por correctos ciertos presupuestos sobre la relación entre propiedad privada e impuestos, que ha sido útil para las políticas neoliberales. Esos presupuestos dieron origen a lo que denomino el paradigma clásico del derecho tributario. 
De acuerdo con el paradigma clásico, los impuestos solamente se justificarían si los individuos consienten en ellos porque van en su interés individual. En este sentido, los impuestos tienen una justificación instrumental: son medios para un fin que va en provecho de los miembros de la sociedad civil. Este paradigma clásico se construye sobre tres elementos: (i) los tributos se justificarían como instrumentos para la recaudación fiscal; (ii) bajo una concepción de los individuos como seres puramente racionales; y (iii) conforme a una concepción de la propiedad privada como derecho natural, opuesta a los tributos.

Uno de los primeros en dar una definición de los impuestos, que llegaría a ser ampliamente aceptada, fue Seligman. Conforme a esa definición, los impuestos son una "contribución obligada de parte de la persona al gobierno, para costear las expensas en que este ha incurrido en el interés común de todos, sin referencia a los beneficios específicos conferidos" (Seligman, 1905, p. 304, énfasis añadido). Así, los impuestos son medios económicos que el gobierno puede obtener coactivamente de los contribuyentes, para el financiamiento de sus actividades (Seligman, 1905, p. 304). ${ }^{7}$ Se trata de una definición propia de este paradigma puesto que es suficientemente general para ser independiente de toda política tributaria particular y, por consiguiente, de todo tipo particular de justificación política. ${ }^{8}$

Según esta definición, los impuestos han de ser aceptados por individuos racionales, de modo que su propiedad privada sea respetada, vale decir, las personas contribuyen y así "dan para ayudar a conseguir" algo. Entonces, se hace necesario saber por qué razón se contribuye y es esto lo que la segunda parte de la definición intenta explicar. Los impuestos tienen una función y esa función consiste en financiar "las expensas en que se ha incurrido en el interés común de todos".

Mientras que otros pagos o tarifas de carácter obligatorio se justifican en virtud de un beneficio directo para el individuo, o bien porque el pago

Existen otras fuentes de ingresos públicos distintas de los impuestos, tales como la actividad económica de las empresas del Estado, los fondos soberanos de riqueza, la privatización y la deuda pública. Véase, (Ferreiro Lapatza, 2010, pp. 103-136) y (Stiglitz, 2000, p. 43 y ss.).

8 No obstante, hacia el final de la tesis, volveré sobre esta definición para mostrar cómo debiese justificarse la obligación de pagar impuestos de manera independiente respecto de la justificación del gasto público. 
es expresión de una sanción por la realización de un comportamiento indeseado; los impuestos se caracterizan por tener una función consistente en "costear las expensas en que se ha incurrido en el interés común de todos".

Dos buenos ejemplos de la justificación instrumental de la tributación dentro de la tradición contractualista, se encuentran -como era de esperarse- en Hobbes y Locke. En el capítulo XXX del Leviatán, Hobbes se refiere directamente a los impuestos al discutir "el fin para el cual le fue confiado el Poder Soberano, a saber, procurar la seguridad de las personas" (Hobbes, 2010 [1651], p. 201). Incluso si es cierto que Hobbes no habría desarrollado del todo una especie de teoría económica (Levy, 1954), puesto que se ocuparía principalmente de la justificación del poder soberano y de la función de la comunidad política, ello no implica que no haya tenido una justificación de los impuestos (Jackson, 1973). En el Leviatán, los impuestos poseen una justificación clara: han de proporcionar los medios económicos necesarios, que permitirán al representante soberano cumplir con sus funciones. De acuerdo con Dudley Jackson, esto explica que el derecho a cargar al pueblo con impuestos pueda justificarse "en substancia [con la misma] respuesta dada todavía hoy: los impuestos pagan el gasto necesario del poder soberano (el gobierno)" (Jackson, 1973, p. 178).

La misma justificación instrumental de la tributación puede encontrarse en Second Treatise of Government de Locke. Los impuestos han de pagarse para que el gobierno pueda dar protección a los derechos naturales de los individuos: "cada cual que disfrute de su parte de la Protección, debiese pagar a su Estado su proporción para el mantenimiento de este" (Locke, 1980 [1690], pp. Cap. 11, \$139). Por supuesto, hay diferencias entre las formas en que Hobbes y Locke justifican la concepción contractualista del Estado como mecanismo para dejar atrás el estado de naturaleza. En relación con los asuntos discutidos aquí, estas diferencias tienen consecuencias para la justificación y la protección de los derechos naturales. No obstante, más allá de tales diferencias, ambos defienden una justificación instrumental de los impuestos, para ir en beneficio directo de los individuos que "firman" el contrato social.

9 Por cierto, no todos estarían de acuerdo con esto. Por ejemplo, para las finanzas públicas los impuestos son (des)incentivos económicos. 
Al margen de los ejemplos históricos, la justificación instrumental de la tributación en las teorías contractualistas de Hobbes y Locke sigue siendo la principal justificación de los impuestos. Persiste todavía en las teorías de las finanzas públicas y en las recientes teorías de la justicia. El lenguaje ha cambiado con el tiempo, pero los impuestos continúan siendo entendidos primariamente como instrumentos para la recaudación de ingresos para el gasto público. Son el mecanismo por medio del cual los individuos contribuyen al financiamiento de los bienes públicos.

No debiese resultar una sorpresa, entonces, que dos de las principales teorías de la justicia contemporáneas mantengan una comprensión instrumental de los impuestos. Tanto Rawls en A Theory of Justice como Nozick en Anarchy, State, and Utopia, defienden versiones instrumentales de los impuestos. ${ }^{10}$

Para Rawls, los impuestos son instrumentalmente relevantes para su concepción de la justicia distributiva. Basta con decir aquí que Rawls asigna a los impuestos dos funciones, una correctiva y una puramente distributiva (Rawls, 1999). De acuerdo con la categorización de las actividades del Estado desarrollada por Rawls, los sistemas tributarios son un instrumento para corregir las distribuciones producidas por el mercado (las que en principio solo persiguen lograr la mayor eficiencia). Todavía más, los impuestos son el mejor mecanismo para lograr cierta justicia distributiva en la sociedad (conforme a la rama de "distribución" del gobierno), por la vía de corregir la distribución del mercado y elevando la recaudación requerida para conseguir exactamente aquello que la justicia exige (Rawls, 1999, pp. 245-246). Lo que aclara la aproximación instrumental a los impuestos sostenida por Rawls, es que para él en una sociedad bien ordenada, la función de los impuestos consiste exclusivamente en obtener ingresos fiscales (Rawls, 1999, p. 246). Esto lleva a Rawls a sostener que los impuestos son instrumentos económicos dejando la política tributaria fuera de las instituciones básicas de una sociedad justa.

Lo mismo puede decirse de la teoría de la justicia de Nozick. Tanto así que, para él, los impuestos son pagos voluntarios para financiar las actividades que los individuos asignan al Estado mínimo. De esta manera, la

${ }^{10}$ Insisto en que esto no es lo mismo que decir que ellos defiendan las mismas políticas tributarias, porque no lo hacen. 
justificación de los impuestos se encuentra en que son instrumentos para la recaudación de ingresos y el financiamiento del gasto público. Nozick, entonces, sigue la comprensión común a la gran mayoría de las teorías liberales de la justicia, independientemente del nivel de redistribución o del régimen de propiedad que cada una de ellas defienda en cuanto al uso de los impuestos. La diferencia es que aquellos que defienden un Estado mínimo, solamente aceptarán el nivel de redistribución que se encuentre moralmente justificado para la defensa de los derechos naturales de los individuos, mientras que quienes defienden una mayor redistribución, buscarán obtener mayores ingresos fiscales para asegurar niveles de justicia distributiva conforme a un principio de justicia diferente al de los intercambios voluntarios. ${ }^{11}$

Como anuncié más arriba esta concepción puramente instrumental de los impuestos descansa en otros dos presupuestos más generales, propios de las concepciones del mundo liberal en el siglo XVII. El segundo es uno sobre la naturaleza de los hombres. Según esta concepción los individuos son seres puramente racionales que se caracterizan por tener un razonamiento instrumental en cuanto a los fines que consideran valiosos, guiados por su autointerés. ${ }^{12}$ Para esta concepción, los individuos son personas o seres "con cierto estatus moral, o un portador de derechos". Este estatus moral requiere o presupone "ciertas capacidades", en particular, que este ser "adopte planes de vida" y que sus decisiones puedan ser "atribuibles a él". Para esta concepción de la persona, "[l]a razón es y debe ser primariamente instrumental” y por consiguiente, "[s] u mundo está constituido por medios potenciales, que entiende con vistas a controlarlo" (Taylor, 1985, p. 112). Según Charles Taylor, bajo esta concepción del individuo, la libertad con-

${ }^{11}$ Otro ejemplo de cómo la justificación instrumental de los impuestos ha permeado todos los posibles argumentos a favor de los impuestos, puede encontrarse en (Holmes \& Sunstein, 2000). Según ellos, todo derecho (negativo o positivo) implica que el Estado debe invertir cierta cantidad de dinero en su protección, o, como lo ponen ellos, "los derechos cuestan dinero" (p. 15). Desde la perspectiva defendida por Holmes y Sunstein, todo derecho es un derecho positivo mientras exija alguna acción de parte de alguien para su protección y exigibilidad (capítulo I).

${ }^{12}$ Existen muchas aproximaciones diferentes que podría adoptar para elaborar el argumento que intento construir aquí. He optado por seguir el trabajo llevado a cabo por Charles Taylor. 
siste en someter al mundo a los deseos o propósitos de los agentes (1985, p. 112). Bajo una de las posibles variantes de esta concepción, quizá la más exitosa en términos de su persistencia en la modernidad, las personas se ocupan de maximizar su utilidad individual.

Se supone que esta concepción de la persona y las consecuencias que de ella se siguen, presenta una explicación de la racionalidad humana más realista o naturalista que aquella propia del mundo religioso o premoderno. La autoridad de las normas (morales o jurídicas) depende de que ellas operen de conformidad a la racionalidad humana en los términos ya explicados: las normas han de ser obedecidas solo en la medida en que hacerlo sea racional para el individuo. ${ }^{13}$ Esto explica por qué razón, para algunos teóricos, las políticas y las leyes han de ser diseñadas conforme a los lineamientos que todo individuo racional podría aceptar. $\mathrm{O}$ bien, si lo que se quiere es conseguir fidelidad de parte de los individuos, lo anterior pone en evidencia la manera en que esas políticas y leyes actúan en su propio autointerés. ${ }^{14}$

El tercer elemento del paradigma clásico del derecho tributario resulta, hoy en día, familiar y corresponde a la idea de que la propiedad privada es un derecho natural. El origen de esta idea ha de encontrarse, otra vez, en el siglo diecisiete, en las teorías contractualistas del Estado, que justifican la existencia de este asignándole la función de proteger los derechos naturales de las personas. También existen aplicaciones contemporáneas de esta idea, siendo el argumento libertario de Nozick en Anarchy, State, and Utopia, la más notable de ellas. Este es, tal vez, el elemento más característico del paradigma clásico a partir del cual se exige una justificación para los tributos, puesto que en caso contrario serían equivalentes a un "robo coactivo del Estado".

Por falta de espacio, no profundizaré aquí en la comprensión que estas teorías tienen de la propiedad como derecho natural y solo recurriré al conocimiento general que se tiene de ellas.

${ }^{13}$ Para una lectura similar, vid, (Dworkin, 2011, pp. 15-19). Para una idea diferente acerca de lo que implica la racionalidad en relación con las razones y la moral, vid, (Gardner, 2007).

$14 \mathrm{Vid}$, (Wenzel, 2003). En materia de impuestos, la versión más básica de esta concepción de las personas lleva a una comprensión de la relación entre el gobierno y los ciudadanos-contribuyentes, como una en la que cada cual lucha por establecer un sistema tributario en las condiciones que más lo beneficie desde un punto de vista económico. Un muy buen ejemplo de la aplicación de estas ideas puede encontrarse en (Brennan \& Buchanan, 2000). 
Este paradigma clásico del derecho tributario dio origen a la forma institucional del derecho tributario actual. Esa forma institucional se ha sistematizado bajo la teoría general del derecho tributario. Para esta teoría general, el deber jurídico del contribuyente de pagar impuestos tiene un derecho correlativo, esto es, la pretensión ejecutable del Estado para el cobro en dinero de los impuestos. Esta relación entre el Estado y el contribuyente transforma el deber tributario en una relación jurídica. Según la teoría general del derecho tributario, en esta relación jurídica, el hecho imponible representa la voluntad del Estado. El hecho imponible (HI) contiene la descripción de los factores relevantes y las condiciones de operación (CO) según las cuales el contribuyente $(\mathrm{C})$ tendrá una obligación legal específica de pagar $(\mathrm{P})$ un cierto monto de impuestos. Esta es la forma en que $\mathrm{P}$ por $\mathrm{C}$ se expresa en el derecho tributario. Sin embargo, para que $\mathrm{C}$ deba $\mathrm{P}$ es necesario que las $\mathrm{CO}$ den paso al $\mathrm{HI}^{15}$ En esta estructura de $\mathrm{P}$ se abre un gran espacio para la elusión tributaria, porque queda mucho espacio para que $\mathrm{C}$ no realice el $\mathrm{HI}$ por cualquier razón, incluyendo la intención de eludir el HI, lo que implica no P. En otras palabras, $\mathrm{P}$ es una obligación condicional sujeta a la realización del HI. Incluso para aquellas teorías que aceptan una interpretación substantiva del HI, la estructura de la teoría general del derecho tributario es un límite para la interpretación analógica o la interpretación de acuerdo con la función del derecho tributario, puesto que sin la satisfacción del HI no existe una obligación legal de pagar impuestos. Bajo esta estructura la protección de la propiedad privada se encuentra en una posición de privilegio comparado con la obligación legal de pagar impuestos.

\section{La justificación liberal igualitaria de los impuestos}

En la tradición liberal igualitaria se encuentra la defensa actual más sofisticada de los sistemas tributarios progresivos. Dentro de esa tradición quienes han dedicado más atención a la justificación de los impuestos fueron Murphy y Nagel en su libro The Myth of Ownership. Según ellos, un pro-

${ }^{15}$ Según Hensel, la obligación legal de pagar impuestos "nace con la realización del hecho imponible" (Hensel, 2005, p. 154). 
blema constante en las discusiones sobre justicia y política tributaria es la "miopía", consistente en asumir que "la justicia de los sistemas tributarios [es] un asunto político distinto e independiente. [...] Puesto que aquello que cuenta como justo en los sistemas tributarios, no puede ser determinado sin considerar cómo el gobierno asigna sus recursos" (Murphy y Nagel, 2002, p. 14) Así, aplicando un criterio económico para medir la justicia distributiva, lo que resulta relevante no es solo establecer un principio de justicia conforme al que podamos determinar cuánto de impuestos debe pagar cada contribuyente, sino que debemos evaluar la posición final en la que se encuentran los individuos tras un ciclo de distribución. La cuestión crucial, por lo tanto, consiste en determinar cuánto contribuye una persona y cuántos recursos le transfiere el gobierno a esa misma persona. La solución que proponen Murphy y Nagel al problema de la miopía supone incluir la discusión sobre justicia en materia tributaria en una discusión general sobre la justicia de un sistema económico particular, vale decir, mirar el esquema general de recaudación y de gasto público.

El segundo elemento central en el argumento de Murphy y Nagel consiste en notar que la discusión sobre justicia de los sistemas tributarios se funda en una equivocación al asumir que la base sobre la que se discute sobre equidad tributaria da por sentado que la distribución de mercado es justa ${ }^{16}$, independiente de los efectos de los impuestos y del esquema convencional de derechos. Ellos llaman a este error "libertarianismo de cada día" (Murphy y Nagel, 2002, pp. 15, 31-37) Abandonar el "libertarianismo de cada día" supone entender que la propiedad privada es un derecho convencional (un hecho institucional), cuya definición y contenido depende de arreglos institucionales (incluyendo los impuestos), que se justifican de acuerdo con una determinada teoría de la justicia (y, por consiguiente, conforme a una concepción particular de la justicia distributiva).

Estos dos elementos del argumento (que la justicia tributaria es una dimensión de la justicia distributiva como justicia económica y que los derechos de propiedad están definidos por un complejo esquema de reglas, entre las cuales se incluyen los impuestos), permiten a Murphy y a Nagel

${ }^{16}$ En especial los criterios de equidad que intentan proveer de distintas concepciones sobre lo que debería entenderse por equidad vertical y equidad horizontal en materia tributaria. 
situar el argumento en la discusión acerca de cuál es la mejor concepción de la justicia distributiva (Murphy y Nagel, 2002, p. 173). Si seguimos el argumento de Murphy y Nagel, hemos de concluir que no podemos discutir sobre justicia pre- o posimpuestos; sino que solo podemos entender que el arco de una concepción de la justicia distributiva cubre la discusión acerca de la tributación y la propiedad privada.

Todas aquellas preguntas normativas acerca de cuáles impuestos se justifican y cuáles no, deben ser interpretadas [...] como preguntas acerca de cómo debe el sistema definir esos derechos de propiedad, que se presentan en las distintas transacciones -de empleo, donaciones, contrataciones, inversiones, compra y venta- sujetas a impuestos. (Murphy y Nagel, 2002, p. 74) $)^{17}$

En definitiva, entonces, si seguimos el argumento y el análisis propuestos por Murphy y Nagel, deberíamos aceptar que los sistemas tributarios cumplen dos funciones principales: (i) la definición de la división entre lo público y lo privado; y, (ii) determinan la distribución del producto social entre propiedad privada y bienes públicos (Murphy y Nagel, 2002, p. 76).

El problema con estas justificaciones de los impuestos dentro de un marco general de justicia distributiva es que los sistemas tributarios y los impuestos en particular, se justifican a tal nivel de abstracción que pierde sentido discutir sobre la institución tal como la conocemos. Murphy y Nagel, en definitiva, no justifican la existencia de los impuestos, sino que la de cualquier instrumento capaz de lograr niveles de distribución mediante redistribución. La imaginación institucional limitada que poseemos hace que contingentemente esta función sea desempeñada por los impuestos, pero no hay ningún valor interno en la institución que la justifique ni mucho menos nos dicen la forma jurídica en que las obligaciones tributarias deberían determinarse.

${ }^{17}$ El mismo argumento es reiterado a lo largo de todo el libro, por ejemplo, pp. 124, 131, 157, 162 y 164 . 


\section{Una alternativa: entender que la legislación tributaria se construye en principios jurídicos}

Ante los problemas de cumplimiento del derecho tributario, han surgido alternativas que buscan superar las limitaciones de la teoría general de la obligación tributaria. La alternativa más relevante hasta ahora es la propuesta por Judith Freedman, que consiste en reemplazar la estructura de la legislación tributaria basada en reglas por una que se construya sobre principios.

La versión de Freedman de la legislación basada en principios (LBP) se presenta como una alternativa a la teoría de la legislación tributaria pensada para captar de mejor manera cuál es la intención legislativa contenida en la ley tributaria. ${ }^{18}$ La LBP se funda en la idea de que existe una diferencia entre la intención legislativa y la noción abstracta de la "voluntad de la ley". La diferencia consiste en que la primera forma parte del derecho dictado por el Parlamento, mientras que la segunda es impuesta al derecho desde "afuera", yendo así más allá de lo que el Parlamento ha establecido en la ley. De acuerdo con Freedman, esta distinción se olvida con facilidad, sin embargo, su importancia no puede ser tan fácilmente desatendida, toda vez que existe siempre en la legislación tributaria una tensión o "choque entre la substancia económica y la realidad jurídica" (Freedman, 2007, p. 73). Esta tensión es el elemento requerido por la legislatura para expresar de mejor manera su intención. Así, siguiendo a Freedman, cualquiera sea la intención del Parlamento -ya se concentre en la substancia económica, o en los conceptos jurídicos-, ella debe establecerse claramente. O bien, si ello no fuere posible, los legisladores debiesen tenerlo en mente y proporcionar, consecuentemente, a los tribunales una guía apropiada para implementar su intención (cualquiera sea su contenido).

La aproximación desde la LBP pareciera proporcionar una buena respuesta a uno de los principales problemas que deben enfrentar quienes defienden una interpretación substantiva de la ley tributaria, esto es, cómo determinar la intención del legislador. Esto resulta especialmente impor-

18 Según Freedman, su concepción de la LBP proviene del trabajo de Avery Jones (Avery Jones, 1996) y del trabajo de Greg Pinder para la Australian Taxation office. Vid, (Freedman, 2010, p. 725). 
tante para aquellos que se preocupan por respetar los valores formales y substantivos asociados al derecho, tales como la democracia, el estado de derecho y la separación de poderes (Freedman, 2010, p. 717), al mismo tiempo que interpretan la ley tributaria más allá de su mera literalidad. Desde esta perspectiva, la pregunta que debe responderse es cómo deben los jueces aplicar la ley, respetando, a la vez, las intenciones del Parlamento.

Lo que explica la importancia de la determinación de la intención del Parlamento, es su relevancia para (la definición o solución de) la elusión tributaria. La premisa que subyace a la afirmación conforme a la cual la elusión tributaria sería legal -esto es, la defendida bajo el paradigma clásico-, es que la letra de las disposiciones legales del derecho tributario considera que ciertos actos (los que forman parte del esquema de elusión) no son CO del HI. Quienes defienden una interpretación substantiva de la ley tributaria, por el contrario, intentarán mostrar que esos mismos actos debiesen ser imponibles de conformidad a la intención del Parlamento. Sin esa determinación, (diría Freedman siguiendo en esto a Honoré (1993)) no existe deber alguno de pagar impuestos, toda vez que las obligaciones tributarias no son obligaciones morales. Del mismo modo, en la medida en que los contribuyentes no vayan en contra de la intención del legislador, la manera en que organicen sus negocios -incluso si lo hacen exclusivamente con el propósito de reducir sus impuestos- debería resultar, consecuentemente, jurídicamente irrelevante.

Una vez que la LBP es adoptada, lo que cambia es la manera en que la legislatura expresa su voluntad. Va desde una detallada expresión "a la manera de una regla" hacia una "a manera de principio". La expresión como principio permitiría a los legisladores asegurarse de la consecución de sus fines y al mismo tiempo, que los tribunales posean cierto margen de acción, que les permita superar los problemas presentados por los casos particulares (Freedman, 2007, pp. 74-75).

Teniendo en mente este tipo de diseño, Freedman sostiene que la legislación tributaria mejoraría, puesto que los legisladores deberían tener una idea muy clara acerca de la política que estarían intentando implementar, para poder expresarla en la forma de principios generales. Al mismo tiempo, los jueces no estarían creando una nueva política tributaria al aplicar tales principios; en este sentido, la LBP se diferencia de la interpretación 
finalista (Freedman, 2010, pp. 721-723). Los principios propios de la LBP no serían "una instrucción amplia para discernir si acaso el propósito de la legislación ha sido truncado, o para definir los motivos del contribuyente"; en lugar de ello, se los establecería para expresar "principios y criterios" claros (Freedman, 2007, p. 75 y 87). Así las cosas, el contenido de las reglas particulares de una determinada regulación estaría sujeto a los propósitos, más amplios, contenidos en los principios. Freedman se cuida de precisar que la LBP no implica que la obligación de pagar impuestos sea justificada solo en base a consideraciones morales, o que dicha obligación "deba basarse en el 'espíritu de la ley"' (2009, p. 8). Por el contrario, si la legislatura explícitamente provee la política general, la judicatura contará con una guía clara para su aplicación, sin contravenir su propia función (Freedman, 2007, p. 87). ${ }^{19}$ Un deber particular y concreto de pagar impuestos sería el resultado de la aplicación de estos principios a un caso particular.

En otras palabras, la propuesta a favor de una LBP conlleva un cambio en la comprensión de la legislación tributaria y de la elusión: desde la determinación e identificación de la conducta contraria a la ley, hacia una definición estructural más amplia de lo que está comprendido por la ley tributaria (o, con el mismo propósito, por el derecho). Por consiguiente, la LBP implica una modificación en la actual distribución de la carga en el derecho tributario: desde que la autoridad recaudadora debe demostrar "que algo se encuentra comprendido por una disposición; hacia que, ahora, sea el contribuyente quien debe mostrar que su caso se encuentra específicamente excluido" (Freedman, 2010, p. 725). Por lo tanto, la LBP es una solución indirecta a la elusión tributaria. Debido a que redefine la manera en que se determina el deber de pagar impuestos, ella reduce el espacio abierto por la ausencia del derecho.

La propuesta de Freedman de una LBP es aparentemente promisoria. En síntesis, ella abre la posibilidad de una nueva comprensión del derecho tributario, bajo la cual los contribuyentes no pueden escudarse tras la letra de la ley. Esto se consigue, modificando la estructura del derecho tributario,

19 Según Freedman, las únicas restricciones aplicables en este caso son aquellas derivadas del ejercicio de la función judicial. El Parlamento no debiese esperar que los tribunales desarrollen políticas cuando ellos no tienen las potestades para hacerlo. (Freedman, 2007, pp. 88-89). 
moviéndose desde "las reglas estrictas" hacia “principios más amplios", que contienen directrices de la política tributaria para la judicatura. Al mismo tiempo, ella pareciera salvaguardar los valores tradicionalmente asociados al Estado de derecho, tales como la claridad, la certeza y la generalidad. Además, no necesita apoyarse en argumentos morales para justificar un deber jurídico de pagar impuestos, puesto que para la LBP, basta con que la intención de la legislatura a ese respecto se encuentre contenida en la ley (cualquiera sea la estructura que adopte). La LBP supone que mientras exista legislación, vale decir, una norma universal que contenga una decisión autoritativa, de la aplicación de dicha norma, surgirá un deber particular de pagar impuestos.

No obstante lo promisoria que pareciera ser la propuesta de Freedman, la LBP resulta problemática sobre dos frentes: (i) bajo la LBP, el derecho tributario deviene una categoría vacía, puesto que en ella no hay contenido substantivo (se trataría de un concepto nominal); y (ii) pone en peligro la distinción entre legislación y adjudicación. Las consecuencias de estos dos problemas son (a) que el derecho tributario carece de legitimación, puesto que la LBP crea un hiato entre forma y substancia; y (b) que no hay derecho tributario a ser aplicado en un caso particular, sino simplemente legislación específica.

La legislación basada en principios (LBP) de Freedman, sin embargo, no constituye una auténtica alternativa a la teoría general del derecho tributario puesto que sigue fundamentándose en el paradigma clásico. En este sentido, además de un cambio en la forma jurídica (para adoptar la LBP) se hace necesario revisar o modificar la substancia subyacente, esto es, el paradigma clásico del derecho tributario. Si mi argumento es correcto, entonces se siguen de él dos conclusiones: (i) existe una relación de dependencia entre el paradigma clásico y la teoría general del derecho tributario (entre substancia y forma); y (ii) no pueden resolverse los problemas de la segunda, sin hacerse cargo del contenido del primero. 


\section{Una reconstrucción alternativa de la racionalidad del derecho tributario en líneas de la filosofía del derecho de Hegel}

Para poder redefinir la comprensión que tenemos del derecho tributario bajo el paradigma clásico y así proveer de una racionalidad substantiva distinta a la instrumental que critiqué más arriba, sostendré que la mejor comprensión del derecho tributario supone entenderlo como la forma institucional de una práctica con un bien interno: el reconocimiento recíproco.

Según Alasdair MacIntyre una práctica consiste en cualquier forma coherente y compleja de actividad humana cooperativa, establecida socialmente, mediante la cual se realizan los bienes inherentes a la misma mientras se intenta lograr los modelos de excelencia que le son apropiados a esa forma de actividad y la definen parcialmente, con el resultado de que la capacidad humana de lograr la excelencia y los conceptos humanos de los fines y bienes que conlleva se extienden sistemáticamente. (MacIntyre, 2001, p. 233)

En After Virtue, MacIntyre sostiene que en las actividades humanas pueden encontrarse bienes internos y bienes externos ${ }^{20}$ Los bienes internos tienen dos características: (a) solamente pueden ser especificados por referencia a la práctica de la cual forman parte; y (b) "solo pueden identificarse y reconocerse participando en la práctica en cuestión” (MacIntyre, 2001, p. 235) Estos son "bienes genuinos" porque son "fines que vale la pena perseguir por su propio bien" (MacIntyre, 1999, p. 66) Los bienes externos, en cambio, son bienes que se obtienen al participar de la práctica porque están “extern[a] y contingente[mente] unidos" (MacIntyre, 2001, p. 234) a la práctica. En este sentido, "[e]stas cosas solamente son bienes qua medios para conseguir algo más que es un bien en sí mismo" (MacIntyre, 1999, p. 66). El ejemplo de MacIntyre es el de alguien que quiere enseñar cómo jugar ajedrez

20 En un libro posterior Dependent Rational Animals, MacIntyre añade un tercer tipo de bienes, aquellos relacionados con el desarrollo humano [human flourishing], a saber, bienes que constituyen bienes para nosotros qua seres humanos. Estos son los bienes que nos permiten ordenar los bienes internos y externos (MacIntyre, 1999, p. 67). 
a un niño que está más interesado en los caramelos que en el ajedrez. Se le podría ofrecer dinero al niño para comprar caramelos, a fin de motivarlo a jugar primero y luego para que continúe, cada vez que gane en el juego. El profesor espera que el niño adquiera un "gusto" por el juego, para que acabe jugando no por el dinero (para comprar caramelos), sino por amor al ajedrez. En este ejemplo, el dinero y los caramelos son bienes externos respecto de los bienes internos del ajedrez, y el niño podría buscar adquirirlos incluso mediante trampas. Sin embargo, la expectativa del profesor es que, con el tiempo, el bien que hay en jugar ajedrez se mostrará y realizará, de manera que el niño llegará a jugar ajedrez porque le gusta. Las prácticas con bienes internos requieren de participación en ellas, para que así la persona que participa llegue a aprender el bien dentro de la práctica. La manera en que compartimos ciertos estándares y propósitos que caracterizan a las prácticas, define la manera en que nos relacionamos unos con otros.

Para MacIntyre, las prácticas deben distinguirse de otros dos modos posibles de actuar en el mundo, con los cuales se las podría confundir ${ }^{21}$ Las prácticas son diferentes de las habilidades técnicas. A pesar de que estas últimas resultan relevantes para lograr los bienes de las prácticas, carecen de un importante aspecto propio de las prácticas. Los fines y los bienes de las prácticas cambian, puesto que son la expresión de los bienes internos y de las capacidades humanas relacionadas con ellos. En este sentido, los fines y objetivos de una práctica mutan debido a que una práctica tiene una historia y su propio desarrollo exige que supere dicha historia. Por el contrario, una habilidad técnica tiene un uso limitado en relación con un fin particular fijado. Una habilidad técnica cambia ya porque no es adecuada para lograr ese fin particular, ya porque el fin ha cambiado. Sin embargo, no hay en este caso una relación histórica con una tradición.

La segunda diferencia es respecto de las instituciones. MacIntyre sostiene que las prácticas son diferentes y no deben confundirse con éstas. Según MacIntyre, las prácticas se refieren a bienes internos y las instituciones, a bienes externos. Esta es una diferencia fuerte, toda vez que MacIntyre establece que las instituciones se relacionan "necesariamente" con los bienes externos, tales como el dinero u otros bienes materiales y la

${ }^{21}$ En los párrafos a continuación sigo a (MacIntyre, 2001, pp. 255-260). 
distribución del poder. Dado que estos son bienes, "nadie puede despreciarlos sin caer en cierto grado de hipocresía” (MacIntyre, 2001, p. 243); no obstante, no son virtudes. Esto es así porque las instituciones son siempre competitivas. Pero lo que diferencia a las prácticas de las instituciones es algo que, simultáneamente, explica porqué se encuentran estrechamente relacionadas. Para MacIntyre, las instituciones están necesariamente conectadas a los bienes externos porque ellas son las "sustentadoras" de las prácticas. Para poder sostenerse en el tiempo, las prácticas requieren de las instituciones. En esta estrecha relación radica también un riesgo. Las prácticas pueden sucumbir a "la codicia de la institución, donde la atención cooperativa al bien común de la práctica es siempre vulnerable a la competitividad de la institución" (MacIntyre, 2001, p. 241).

Si entiendo correctamente a MacIntyre, entonces los bienes externos de las instituciones pueden ser útiles para lograr y sostener los bienes internos de las prácticas. Sin embargo, y ésta es una diferencia importante respecto de la justificación meramente instrumental de las instituciones provista por el individualismo liberal, las instituciones no se explican nada más por sus bienes externos. Ellas deben ser la expresión de las prácticas que sostienen y esto implica que se encuentran, también, vinculadas a los bienes internos que caracterizan a estas últimas. Esto es lo que interpreto de MacIntyre cuando dice que "[a] su vez, las virtudes son fomentadas por ciertos tipos de instituciones sociales y amenazadas por otros” (2001, p. 243).

\subsection{Reconocimiento, solidaridad e impuestos}

La búsqueda de un bien interno de la práctica requiere una noción más compleja de los individuos en las sociedades modernas contemporáneas que la del paradigma clásico, que sea capaz de combinar los elementos individuales y sociales que los caracterizan. Esta es la tarea que emprendió Hegel, la de reconciliar a los individuos modernos con las instituciones en que viven. Para esta noción compleja, los individuos nunca se encuentran aislados y siempre forman parte de una comunidad política. En lugar de ser un individuo racional el que decide ingresar al contrato -y en esto parafraseo las ideas de MacIntyre en Dependent Rational Animals, el individuo 
solo puede llegar a desarrollar su razonamiento práctico como resultado de una serie de complejos procesos interrelacionados, que tienen lugar al interior de las relaciones e interacciones sociales. La noción compleja podría ser interpretada como un intento de conciliar la idea antigua de una comunidad ética, con la noción moderna del individuo.

No existe una única definición dominante de la noción compleja del individuo $y$, por el contrario, de hecho, se han proporcionado diversos argumentos. Para mencionar unos pocos ejemplos entre los pensadores contemporáneos, MacIntyre sostiene que solamente podemos desarrollarnos como seres humanos si cultivamos cierto tipo de razón práctica, que proviene de nuestra naturaleza vulnerable y dependiente ${ }^{22}$; según Honneth, quien combina el modelo teórico de las luchas sociales de Hegel con la psicología social de Mead, la posibilidad de llegar a ser un individuo completamente autónomo depende de ciertas formas de reconocimiento social ${ }^{23}$; y finalmente, para Castoriadis, la autonomía individual y colectiva no pueden sino ser entendidas como un proyecto político (socialista) revolucionario (un proyecto que se apoya en dos previos momentos históricos en los que las instituciones fueron cuestionadas, esto es, la antigua Grecia y el final de la Alta Edad Media en Europa occidental). ${ }^{24}$

Para los propósitos de este argumento, es suficiente con desarrollar dos puntos. Primero, mostrar cómo es que, de acuerdo con estas teorías, la interacción con otros individuos explica la manera por medio de la cual podemos llegar a ser sujetos autónomos. En otras palabras, la primera tarea consiste en explicar la idea de reconocimiento. Con este propósito, sigo la teoría social de Honneth, a la cual también añadiré algunas de las ideas

22 Argumento que desarrolla en (MacIntyre, 1999).

${ }^{23}$ Para la explicación general de esta idea de Honneth, ver (Honneth, 1995). Ver también (Anderson \& Honneth, 2005), donde, aplicando la estructura del reconocimiento social, los autores critican la concepción que Rawls tiene de la autonomía.

${ }^{24}$ Ver (Castoriadis, 1997, p. 80 y ss.); (Castoriadis, 1991, pp. 124-142); (Castoriadis, 2007, p. capítulo 5); (Castoriadis, 2010, pp. 3-4). Para Castoriadis, la política revolucionaria consiste en "una praxis que toma por objeto la organización y orientación de la sociedad, en tanto fomenta la autonomía de todos sus miembros y reconoce que esto presupone una transformación radical de la sociedad, que solamente será posible, a su turno, por medio de la actividad autónoma de los individuos". (Castoriadis, 1997, p. 77). 
de MacIntyre ${ }^{25}$ En segundo lugar, exploro la relación entre impuestos y reconocimiento.

Debates recientes en el ámbito de la filosofía política han rescatado el término "reconocimiento" de las manos de Hegel en su Fenomenología del Espíritu ${ }^{26}$ Siguiendo a Hegel, Honneth identifica tres "formas" (1995, p. 25) o "esferas" (Fraser y Honneth, 2003, p. 138) de reconocimiento. Cada una de estas esferas representa una etapa diferente en la cual un ser humano puede llegar a ser sujeto de reconocimiento. En cada una de estas etapas, existen diversos modos de reconocimiento y diferentes contenidos a ser reconocidos, dependiendo del concepto de persona a encontrarse en cada una. Las distintas etapas en las cuales un ser humano puede ser sujeto de reconocimiento son: el individuo, la persona y el sujeto. Los modos de reconocimiento para cada una de estas etapas son: la familia, la sociedad civil y el Estado. El contenido a ser reconocido en cada una de estas esferas también es diferente. En la familia, el individuo es reconocido por medio de una relación afectiva que cubre sus necesidades concretas; en la sociedad civil, el derecho reconoce a una persona como una persona jurídica abstracta y por consiguiente, se la reconoce en términos de su autonomía formal; finalmente, en el Estado, los sujetos son reconocidos conforme a su particularidad individual como "concretos universales" a través de la solidaridad (Honneth, 1995, p. 25) La finalidad de estas etapas intersubjetivas de reconocimiento, según Honneth, consiste en lograr la autorealización del hombre. Cada una de estas etapas contiene "exigencias normativas que

${ }^{25}$ No desarrollo la teoría de Castoriadis debido a que ésta depende en alto grado de ideas psicoanalíticas y mostrar su conexión con los arreglos sociales existentes resultaría demasiado exigente para el argumento presentado aquí.

${ }^{26}$ Para una informativa revisión de las ideas de Hegel acerca del reconocimiento y de su aplicación a la filosofía práctica contemporánea, ver (Siep, 2010). Existe cierto debate en la literatura acerca del origen del término reconocimiento. Siep, por ejemplo, sostiene en su artículo que el concepto se encuentra originalmente en Fichte, aunque Hegel extiende su aplicación más allá de las relaciones intersubjetivas directas. En la filosofía práctica contemporánea, Siep distingue tres usos diferentes que se le han dado al término: (i) como respeto mutuo entre personas autónomas; (ii) en el contexto de la psicología social y de la investigación filosófica sobre el desarrollo de la identidad; y (iii) entre diversas cosmovisiones y culturas en las comunidades multiculturales. (Siep, 2010, pp. 113-114). 
son, estructuralmente hablando, internas a la relación de reconocimiento recíproco" (Honneth, 1995, p. 92).

Así las cosas, ¿cómo es que estas ideas se relacionan en el análisis de la tributación como una práctica? Para desarrollar nuestras máximas capacidades como seres humanos, dependemos de los otros y de las complejas interrelaciones sociales que hemos construido con quienes interactuamos. La esfera del amor -o las primeras etapas de nuestra dependencia animalestablece las formas en las cuales hemos de relacionarnos con los otros en nuestra vida temprana, en atención a nuestras necesidades concretas. A pesar de lo importante que resulta este espacio para el amor propio básico, no constituye la principal preocupación de aquellas prácticas que son institucionalizadas. Las esferas de reconocimiento que más estrechamente se relacionan con las prácticas y las instituciones son las del derecho y de la solidaridad. Por tanto, si estamos buscando una justificación de la tributación como práctica bajo este esquema, entonces necesitamos encontrar el bien que hay en la práctica (lo que proporcionará los fundamentos para que la práctica se convierta en una institución).

La justificación meramente instrumental de las instituciones, por consiguiente, niega la conexión existente entre nuestros arreglos institucionales y las interacciones sociales, al igual que la forma en que éstos transforman nuestras vidas. Y lo que la justificación meramente instrumental niega es, precisamente, el punto defendido por Honneth y MacIntyre, esto es, que la posibilidad de desarrollarnos completamente como individuos es una empresa colectiva. De esta manera, la justificación meramente instrumental de los impuestos niega la idea misma de dependencia recíproca. Ésta es todavía una afirmación demasiado general. Intentaré especificarla, desarrollando más profundamente la relación entre impuestos y (las esferas de) reconocimiento. Con este propósito, las dos esferas de reconocimiento corresponderán, lógicamente, al derecho y al Estado.

Los sistemas tributarios son parte de los arreglos conforme a los que se distribuyen bienes entre los miembros de una comunidad política y constituyen un aspecto importante del vivir juntos, puesto que aseguran las condiciones materiales para hacerlo posible. En este sentido, esta práctica es parte de una evolución histórica, dentro de la cual el reconocimiento en 
las esferas del derecho y del Estado han hecho posible el desarrollo libre de los sujetos permitiendo su autorealización siendo parte de las instituciones que caracterizan al Estado moderno. La práctica de los impuestos es parte de una vida ética y es esencial para la solidaridad.

Se trata de una práctica en la que hay un bien que es bueno para nosotros qua seres humanos. Aplicando las ideas de MacIntyre, esto significa que es posible encontrar en la tributación un bien que nos permite desarrollarnos como seres humanos, esto es, como animales capaces de desarrollar completamente la razón práctica. De manera más precisa, los sistemas tributarios tendrían que ser una práctica en la que podamos aprender acerca de las virtudes de la "dependencia mutua" (MacIntyre, 1999, p. 10). Por supuesto, sería un error leer en esto que los sistemas tributarios son la única práctica en la cual aprendemos acerca de esas virtudes. Mi posición es más modesta que eso. Creo que basta con mostrar que es una práctica en la que tenemos la posibilidad de aprender aquellas virtudes. Como tal, esta posibilidad entrega una mejor explicación y comprensión de los sistemas tributarios que supera la comprensión que predomina hoy. La institucionalización de los sistemas tributarios justificada de forma instrumental, combinada con las economías de mercado neoliberales actualmente existentes, produce un resultado explosivo que no deja espacio posible a la solidaridad o a las virtudes de la dependencia recíproca y solo da cuenta de la institución haciéndola opresiva.

\subsection{Impuestos como propiedad privada, o propiedad privada como impuestos}

Un último paso para dejar atrás el paradigma clásico consiste en redefinir la relación entre propiedad privada e impuestos. Para eso resulta adecuado partir por asumir que hoy no basta con justificar la propiedad privada como un derecho natural, sino que es necesario encontrar razones para su institucionalización. Así, en los sistemas jurídicos contemporáneos la propiedad privada supone una decisión previa acerca del sistema de asignación de propiedad que la comunidad política adoptará. En este sentido, Jeremy Waldron sostiene que el concepto de propiedad privada corresponde a 
"un sistema de reglas que regulan el acceso a y el control de los recursos materiales" (1988, p. 31) Este sistema puede estar configurado bajo diversas formas alternativas de asignar aquellos recursos materiales. Los sistemas más comúnmente conocidos son la propiedad privada, la propiedad colectiva y la propiedad común (Waldron, 1988, pp. 37-42), pero pueden existir otros que pueda permitirse nuestra imaginación institucional.

Siguiendo el análisis de Waldron, los argumentos que se fundan en derechos para reconocer propiedad privada ${ }^{27}$, vale decir, en la protección de un interés individual, pueden ser especiales o generales ${ }^{28}$ Los primeros suponen un hecho contingente o una transacción; los segundos, un interés en sí mismo. En este segundo caso, la propiedad privada es entendida como algo valioso para cada individuo, algo que todos deberían tener. La teoría de la propiedad privada de Hegel es el caso paradigmático de este último tipo de justificación. Para Hegel, la propiedad privada se justifica porque hace posible el reconocimiento recíproco y la libertad individual, la objetivación de la subjetividad individual en el mundo. La propiedad privada, en otras palabras, hace posible la primera expresión de la libertad de los individuos al permitir los medios para el desarrollo de los deseos subjetivos.

Como decía antes en este trabajo, para Murphy y Nagel esta comprensión de la propiedad privada es un punto de partida básico para hablar sobre justicia e impuestos. Para ellos, la propiedad privada es resultado de las reglas que definen los sistemas tributarios. En sus palabras, "la cuestión de los sistemas tributarios no es sobre cómo debe el Estado apropiarse y distribuir lo que ya pertenece a los ciudadanos, sino sobre cómo debe el Estado permitir que se determine la propiedad" (Murphy \& Nagel, 2002, p. 176) El problema con Murphy y Nagel es que no están dispuestos a asumir las consecuencias radicales que se siguen de su argumento, por permanecer anclados en los límites del paradigma clásico.

La radicalidad de asumir que la propiedad privada se justifica por el valor que representa para los individuos y al mismo tiempo que su definición depende del conjunto de reglas que expresan una concepción de

27 Otras justificaciones pueden ser: utilitaristas, consecuencialistas o deontológicas. Véase íbid., cap. 3 y (Murphy \& Nagel, 2002, pp. 42-45).

28 (Waldron, 1988, pp. 115-117, y en general el cap. 114). 
la justicia distributiva, lleva a la conclusión que la propiedad privada y los impuestos son conceptualmente inseparables. ¿Qué ocurre si no solo estamos preocupados de justificar la redistribución para evitar la pobreza como lo hacen los liberales igualitarios, sino que nos tomamos en serio la idea de buscar el valor en la propiedad privada y en los impuestos? Ese valor puede permitir superar las contradicciones sobre las que se construye el paradigma clásico, en especial la que contrapone propiedad e impuestos.

El desarrollo intersubjetivo del sujeto, o la posibilidad de nuestro desarrollo como seres humanos, requiere que reconozcamos derechos cuando ello sea necesario para nuestro autorespeto. El derecho a la propiedad privada es un derecho de este tipo. Si seguimos a Hegel, se trata de un derecho que nos garantiza el espacio para la expresión objetiva en el mundo de nuestra voluntad subjetiva. Esta definición del derecho a la propiedad privada posee un límite intrínseco: el reconocimiento de la propiedad privada de otros. O lo que es lo mismo, asegurar espacios de libertad y desarrollo de la personalidad a todos. Un sistema de propiedad privada y un sistema tributario son las dos caras de una misma moneda, porque los impuestos representan la forma de asegurar libertad para todos; la posibilidad del desarrollo ético de sujetos libres.

Si esto es así, se siguen dos importantes consecuencias. La primera es que no tenemos necesidad alguna de justificar la redistribución. Lo que llamamos redistribución se convertirá en una consecuencia necesaria del reconocimiento de un derecho convencional a la propiedad privada. La redistribución (que afecta la propiedad privada para modificar una distribución previa) debería ser una consecuencia constitutiva de la propiedad privada; tendremos, entonces, una asignación constante de bienes bajo una concepción de la "vida ética". En este sentido el sistema tributario es expresión de solidaridad. Una segunda consecuencia importante es que la obligación de pagar impuestos puede ser explicada sobre nuevos fundamentos. Ella no dependerá más de la voluntad del individuo, sino de la existencia objetiva del derecho a la propiedad privada. Todo individuo al que se le reconozca un derecho de propiedad privada tendrá el deber de pagar impuestos como sujeto que forma parte de un Estado. El deber legal de pagar impuestos no puede justificarse en términos meramente instrumentales; sino que formará parte de la propiedad privada. Esta segunda 
conclusión podría dar un mejor fundamento a la propuesta de Freedman presentada más arriba sobre reconstruir el derecho tributario como legislación basada en principios.

\section{Bibliografía}

Anderson, J., y Honneth, A. (2005). Autonomy, Vulnerability, Recognition, and Justice. En J. Christman y J. Anderson (Eds.), Autonomy and the Challenges to Liberalism. New Essays (pp. 127-149). Cambridge: Cambridge U.P.

Avery Jones, J. (1996). Tax Law: Rules or Principles? Fiscal Studies, 17(3), 63-89.

Brennan, G., y Buchanan, J. M. (2000). The Power to Tax. Analytical Foundations of a Fiscal Constitution. Indianapolis: Liberty Fund.

Brown, W. (2015). Undoing the Demos. Neoliberalism's Stealth Revolution. Nueva York: Zone Books.

Castoriadis, C. (1991). Philosophy, Politics, Autonomy. Essays in Political Philosophy. Nueva York: Oxford U.P.

Castoriadis, C. (1997). The Imaginary Institution of Society. Cambridge: Polity Press.

Castoriadis, C. (2007). Figures of the Thinkable. Stanford: Stanford U.P.

Castoriadis, C. (2010). A Society Adrift. Interviews and Debates, 1974-1997. Nueva York: Fordham U.P.

Crouch, C. (2004). Post-Democracy. Cambridge: Polity.

Crouch, C. (2011). The Strange Non-Death of Neoliberalism. Cambridge: Polity.

Crouch, C. (2013). Making capitalism Fit for Society. Cambridge: Polity.

Dworkin, R. (2011). Justice for Hedgehogs. Cambridge - London: Belknap Press of Harvard University Press.

Ferreiro Lapatza, J. J. (2010). Instituciones de Derecho Financiero. Madrid: Marcial Pons.

Fraser, N., y Honneth, A. (2003). Redistribution or Recognition? Londres: Verso.

Freedman, J. (2007). Interpreting Tax Statutes: Tax Avoidance and the Intention of Parliament. Law Quarterly Review, 123, 53-90. 
Francisco Saffie

Freedman, J. (2009). A GANTIP: Was It Really Such a Bad Idea?. Tax Journal, 9, 8-18.

Freedman, J. (2010). Improving (Not Perfecting) Tax Legislation: Rules and Principles Revisited. British Tax Review, 6, 717-736.

Gardner, J. (2007). Nearly Natural Law. American Journal of Jurisprudence, $52(1), 1-23$.

Harvey, D. (2006). Spaces of Global Capitalism. Londres: Verso.

Harvey, D. (2007). A Brief History of Neoliberalism. Oxford: Oxford U.P.

Hensel, A. (2005). Derecho tributario. Madrid: Marcial Pons.

Hobbes, T. (2010 (1651)). Leviathan. New Haven y Londres: Yale U.P.

Holmes, S., y Sunstein, C. (2000). The Cost of Rights. Why Liberty Depends on Taxes. Nueva York: W.W. Norton y Company.

Honneth, A. (1995). The Struggle for Recognition. The Moral Grammar of Social Conflicts. Cambridge, Mass.: The MIT Press.

Honoré, T. (1993). The Dependence of Morality On Law. Oxford Journal of Legal Studies, 13(1), 1-17.

Jackson, D. (1973). “Thomas Hobbes' Theory of Taxation”. Political Studies, 21(2), 175-182.

Kleinbard, E. (2014). Are Better Than This. How Government Should Spend Our Money. Oxford: Oxford U.P.

Levy, A. (1954). Economic Views of Thomas Hobbes. Journal of the History of Ideas, 15(4), 589-595.

Locke, J. (1980 (1690)). Second Treatise of Government. Cambridge: Hackett Publishing Company.

MacIntyre, A. (1999). Dependent Rational Animals. Chicago: Open Court. MacIntyre, A. (2001). Tras la virtud. Barcelona: Crítica.

Murphy, L. B., y Nagel, T. (2002). The Myth of Ownership. Taxes and Justice. Nueva York: Oxford U.P.

Paus, A. (1994). Economic growth through neoliberal restructuring? Insights from the Chilean experience. Journal of Developing Areas, 29(1), 31-56.

Rawls, J. (1999). A Theory of Justice. Cambridge, Mass.: Cambridge UP. Seligman, E. R. (1905). Essays in Taxation. Nueva York: Columbia U.P. Siep, L. (2010). Recognition in Hegel's Phenomenology of Spirit and Contemporary Political Philosophy. En H.-C. Schmidt am Busch 
y C. Zurn (Eds.), The Philosophy of Recognition. Historical and Contemporary Perspectives (pp. 107-128). Lanham: Lexington Books.

Stiglitz, J. E. (2000). Economics of the Public Sector. Nueva York: W.W. Norton y Company.

Streeck, W. (2012). Citizens as Customers: Considerations on the New Politics of Consumption. New Left Review, 76, 27-47.

Streeck, W. (2014). Buying Time. The Delayed Crisis of Democratic Capitalism. Londres: Verso.

Taylor, C. (1985). The Concept of a Person. En C. Taylor, Human Agency and Language. Philosophical Papers 1 (pp. 97-114). Nueva York: Cambridge U.P.

Waldron, J. (1988). The Right to Private Property. Oxford: Oxford U.P.

Wenzel, M. (2003). Tax Compliance and the Psychology of Justice: Mapping the Field. En V. A. Braithwaite (Ed.), Taxing Democracy: Understanding Tax Avoidance and Tax Evasion (pp. 41-69). Aldershot: Ashgate. 